\title{
Utilizing social marketing and social franchising models to expand access to the progesterone contraceptive vaginal ring
}

\author{
Ishita Chattopadhyay \\ Population Council \\ John Townsend \\ Population Council \\ Saumya RamaRao \\ Population Council
}

Follow this and additional works at: https://knowledgecommons.popcouncil.org/departments_sbsr-rh

Part of the Demography, Population, and Ecology Commons, Family, Life Course, and Society Commons, International Public Health Commons, and the Women's Health Commons How does access to this work benefit you? Let us know!

\section{Recommended Citation}

Chattopadhyay, Ishita, John Townsend, and Saumya RamaRao. 2015. "Utilizing social marketing and social franchising models to expand access to the progesterone contraceptive vaginal ring." Washington, DC: Population Council. 


\section{UTILIZING SOCIAL MARKETING AND SOCIAL FRANCHISING MODELS TO EXPAND ACCESS TO THE PROGESTERONE CONTRACEPTIVE VAGINAL RING}

Ishita Chattopadhyay John W. Townsend Saumya RamaRao COUNCIL 


\section{POPULATION}

\section{COUNCIL}

Ideas. Evidence. Impact.

The Population Council confronts critical health and development issuesfrom stopping the spread of HIV to improving reproductive health and ensuring that young people lead full and productive lives. Through biomedical, social science, and public health research in 50 countries, we work with our partners to deliver solutions that lead to more effective policies, programs, and technologies that improve lives around the world. Established in 1952 and headquartered in New York, the Council is a nongovernmental, nonprofit organization governed by an international board of trustees.

Population Council

4301 Connecticut Avenue, NW, Suite 280

Washington, DC 20008

Tel: +1 2022379400

Fax: +12022378410

popcouncil.org

Suggested citation: Chattopadhyay, I., J.W. Townsend and S. RamaRao. 2015. "Utilizing social marketing and social franchising models to expand access to the Progresterone Contraceptive Vaginal Ring." Washington, DC: Population Council.

\section{UTILIZING SOCIAL MARKETING AND SOCIAL FRANCHISING MODELS TO EXPAND ACCESS TO THE PROGESTERONE CONTRACEPTIVE VAGINAL RING}

This technical report is part of a series of reports investigating the introduction of the PCVR in the context of quality, choice, equity and improved access. Each report provides information about the product and its benefits in addressing the gap in postpartum family planning (PPFP); offers a pathway for marketing and assumes that products will be available from manufacturers and distributors to respond to women's needs in diverse markets. Other reports in this series include:

- An innovative financing model for the Progesterone Contraceptive Vaginal Ring through voucher programs

- Offering Progesterone Contraceptive Vaginal Ring for postpartum women through integrated family planning and immunization services 


\section{Table of Contents}

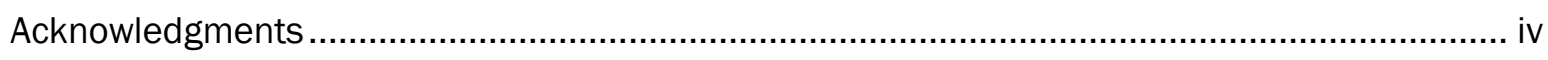

List of Abbreviations....................................................................................................... iv

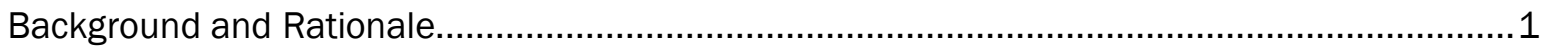

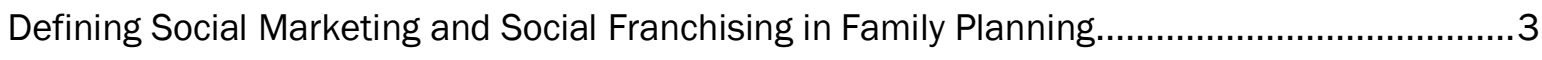

Implementation of the Model in Three Phases ................................................................ 13

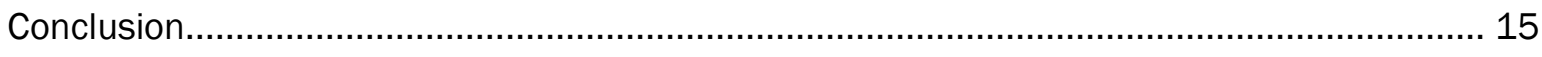

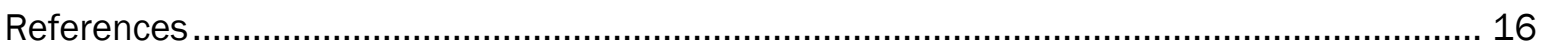

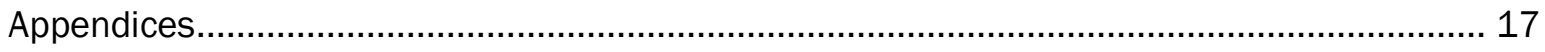




\section{Acknowledgments}

This report was developed under the larger project 'Delivering Contraceptive Vaginal Rings' funded by USAID under the Annual Program Statement number SOL-OAA-13-000024, Agreement number AID-OAAA-13-00075.The project aims to strategically introduce the Progesterone Contraceptive Vaginal Ring (PCVR) as a new contraceptive option for postpartum family planning.

The opinions expressed in this report are those of the authors and do not reflect the views of its funding or implementing agencies.

\section{List of Abbreviations}

$\begin{array}{ll}\text { BCC } & \text { Behavior Change Communication } \\ \text { CHW } & \text { Community Health Worker } \\ \text { DCVR } & \text { Delivering Contraceptive Vaginal Rings } \\ \text { DHS } & \text { Demographic and Health Survey } \\ \text { DKT } & \text { DKT International } \\ \text { DRH } & \text { Department of Reproductive Health } \\ \text { FP } & \text { Family Planning } \\ \text { FP/RH } & \text { Family Planning and Reproductive Health } \\ \text { HIP } & \text { High Impact Practice } \\ \text { IEC } & \text { Information, Education and Communication } \\ \text { IUCD } & \text { Intrauterine Contraceptive Device } \\ \text { LAM } & \text { Lactational Amenorrhea Method } \\ \text { LARC } & \text { Long-acting Reversible Contraceptive } \\ \text { MCH } & \text { Maternal and Child Health } \\ \text { MCHIP } & \text { Maternal and Child Health Integrated Program } \\ \text { MDP } & \text { Market Development Plan } \\ \text { MDG } & \text { Millennium Development Goal } \\ \text { MoH } & \text { Ministry of Health } \\ \text { MSI } & \text { Marie Stopes International } \\ \text { PCVR } & \text { Progesterone Contraceptive Vaginal Ring } \\ \text { PPFP } & \text { Postpartum Family Planning } \\ \text { PSA } & \text { Public Service Announcements } \\ \text { PSI } & \text { Population Services International } \\ \text { RH } & \text { Reproductive Health } \\ \text { SHOPS } & \text { Strengthening Health Outcomes through the Private Sector } \\ \text { SF } & \text { Social Franchising } \\ \text { SM } & \text { Social Marketing } \\ \text { SM/SF } & \text { Social Marketing and Social Franchising } \\ \text { SMO } & \text { Social Marketing Organisation } \\ \text { SFO } & \text { Social Franchising Organisation } \\ \text { TAC } & \text { Technical Advisory Committee } \\ \text { USAID } & \text { United States Agency for International Development } \\ \text { WHO } & \text { World Health Organization } \\ \text { WTP } & \text { Willingness to Pay } \\ & \end{array}$




\section{Background and Rationale}

With the Millennium Development Goals (MDG) ending in 2015, the efforts to achieve the MDG 5 goal of 'Improving Maternal Health' through better access to reproductive health falls short in addressing the of family planning needs low-income postpartum women. According to Demographic and Health Surveys (DHS) conducted in 27 countries, more than $65 \%$ of women who are 0-12 months postpartum and want to delay or avoid pregnancy are not using contraception (Ross and Winfrey, 2001).

The Progesterone Contraceptive Vaginal Ring (PCVR) is an effective, userinitated contraceptive option which helps meet the need for postpartum family planning (PPFP). It is exclusively designed for postpartum breastfeeding women who want to space or delay pregnancies in the first year following childbirth. The PCVR can be used by lactating mothers as early as 6 weeks postpartum and can be easily inserted and removed from the vagina without the need for clinical help or supervision. Each PCVR diffuses $10 \mathrm{mg}$ of natural progesterone per day (which suppresses ovulation). Women can use a ring continuously for up to 3 months and up to 4 rings in the first year following childbirth.

The lack of healthcare infrastructure to support family planning programs coupled with limited access and information on postpartum family planning has led to negative consequences for the maternal and child health following childbirth (USAID, 2011). A total market approach (TMA) is proposed to reach postpartum women across all income brackets in countries where there is a high unmet need for family planning (Barnes et al, 2012).

In recent years, the private sector has become increasingly important for delivering family planning and reproductive health (FP/RH) services and modern contraceptive products to developing countries. Women rely on the private sector because of the perceived better quality of healthcare services, available and trusted brands of products and convenient locations with flexible operating hours (Beyeler, 2013). According to a study conducted by the USAID/SHOPS Project (2013), a substantial proportion of poor women in all regions obtain their family planning from the private sector. Furthermore, PSI (2014) suggests that making investments in the private sector also helps in the long-term sustainability and scalability of FP/RH programs. Expanding contraceptive delivery through the private sector helps manage supply chain systems in an efficient manner. Equipping the private sector to offer a range of high-quality FP services increases contraceptive choice through a variety of outlets and benefits the health system overall (SIFPO, 2012).

Social Marketing and Social Franchising (SM/SF) are recognized high impact strategies to expand service delivery across a wider network of healthcare providers. This high impact practice (HIP) has been recognized as one of the fastest-growing market-based healthcare interventions in the field of reproductive health (USAID, 2013; Schlein and Montagu, 2012; PSI, 2013). 
According to USAID (2011), social franchises (SF) for family planning are branded networks of providers (mostly private) who agree to offer a package of FP/RH services and adhere to quality standards in their practices. They are trained to offer family planning services, and many integrate these services with the maternal and child health services that they already provide. On the other hand, social marketing (SM) approaches are often used to advertise these services and their prices to consumers in low and middle income strata. To expand access to family planning, some providers offer voucher subsidies to the lowest-income consumers to offset the costs of these family planning products and services.

This technical report will describe a social marketing and social franchising model that will be adopted for the introduction and scale-up of PCVR as a PPFP contraceptive option. A methodology for implementation of this model, also referred to as the PCVR-Social Marketing and Social Franchising (PCVR-SM/SF) Model, has been designed to introduce PCVR in the context of choice among other PPFP products and services; equity through provision of services in a range of outlets; varying prices based on affordability of target clients and ensuring quality of care and consistent availability of services. A proposed structure to introduce and integrate PCVR into the SM/SF system has been outlined and described in 3 phases: the design phase, the start-up phase and the scale-up phase.

The model provides guidance on how PCVR can be included into existing SM/SF programs. Examples of existing SM/SF programs include Population Services International (PSI), Marie Stopes International (MSI) and DKT International (DKT) that have the potential to integrate and introduce PCVR through their distribution networks in priority countries.

This technical report may be used by FP/RH service implementers and program managers who wish to implement the PCVR-SM/SF model. The implementing partners or managers have been referred to as the "project" throughout the document. 


\section{Defining Social Marketing and Social Franchising in Family Planning}

Social Marketing (SM) in family planning uses commercial marketing concepts to promote healthy behaviors and provide contraceptive products and services at subsidized rates, mostly in low-income communities (PSI, 2014; O'Sullivan et al, 2007). SM adopts intense marketing, branding and community mobilization approaches through a standardized protocol (MSI, 2011; PSI, 2014; Schlein K. and D.Montagu, 2012). A social marketing organization (SMO) is any entity, formal or informal, responsible for the management and implementation of promotional or distribution activities. The SMOs may include local NGOs, or international non-profit associations (such as Population Services International, Marie Stopes International) or commercial companies (DKT International), consulting firms and government agencies or pharmacies (O'sullivan et al, 2007).

Social Franchising (SF) is a strategy to efficiently expand access to high-quality healthcare that is affordable to underserved populations (PSI, 2014). Social franchises are outlets (e.g., NGOs, clinics, pharmacies, mobile clinics) run by a network of service provider (e.g., midwives, nurses, doctors, pharmacists, community health workers) whose services are standardized and quality-controlled (PSI, 2014). According to Smith (2002), social franchising in FP/RH can employ a wide range of skilled, semi-skilled, unskilled but trainable workers in developing countries to expand access to goodquality, affordable family planning services.

All social franchisees operate under contracts with a common agency or franchisor that aims to provide standardized products and services under a common brand (Schlein and Montagu, 2012). Social franchises typically include the following characteristics: outlets are operator-owned; outlets provide FP/RH services with or without franchise-branded commodities; and payments to outlets are based on services provided or in other words employ pay-for-performance strategies (Schlein and Montagu M, 2012).The franchisees pay a small fee to join the network and receive extensive training on FP/RH services and products. Franchised clinics and healthcare centers have increased access to higher-quality services due to emphasis on rigorous training and monitoring provided by the franchisor. Some of the key roles and responsibilities of the social franchisor include: recruiting qualified franchisees; building a branding and marketing strategy; defining guidelines and protocols;managing the network of providers; conducting outreach activities with franchisees, training franchisees and managing quality assurance standards (PSI, 2014; MSI, 2011).

"Social marketing and social franchising interventions can help achieve:

(1) increased availability of family planning products, (2) increased range of available products at a variety of prices resulting in increased client choice, (3) reduced burden on the public sector by shifting clients who can pay to the private sector, (4) increased family planning program sustainability, (5) better targeting of donor funding, and (6) increased family planning use in general and among underserved populations" (USAID/HIP, 2013). 
While most social marketing organizations also provide services through social franchising outlets, a few organizations may only support social marketing of products that are available at a subsidized price. For example, social marketing organizations such as Population Services Interntional (PSI) and DKT may primarily collaborate with the government and private healthcare facilities to market contraceptive products that are available at subsidized rates across the public and private sector facilities.

Another key consideration while planning social marketing and social franchising programs will be to plan for adequate finances to cover the subsidized FP/RH products and services. The sustainability of social marketing and social franchising often depends on donor or government funding, ongoing technical assistance and subsidized contraceptive supplies for long-term sustainability (Smith, 2002). Donors are more likely to invest in introducing new products to established FP/RH franchises with a positive record of service.

Figure1 (Armand, 2003) illustrates some of the key funding mechanisms of socially marketed products and services. These include donors or financial investors who may provide funding for general operations and provision for subsidized commodities; a franchisor or the central social franchising agency that charges a franchising fee to the franchisees (for being trained and part of the network) and the clients who may pay for minimum services.

\section{FIGURE 1: FUNDING MECHANISMS OF SOCIALLY MARKETED GOODS AND SERVICES}

\section{Financing Model}

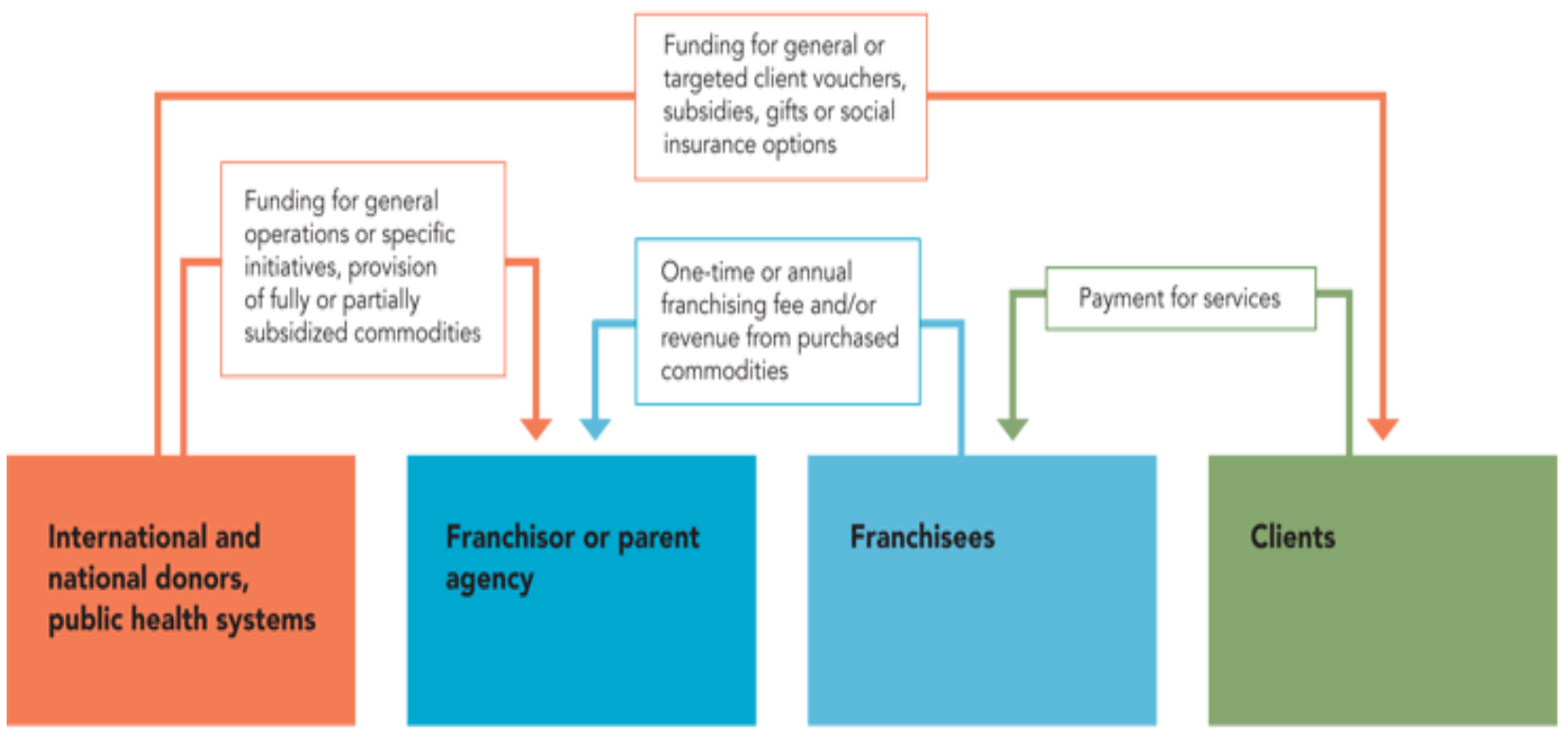

Source: Armand, 2003 
In a comprehensive review of social franchising and social marketing for reproductive health services Beyeler et al. (2013) found that SM and SF help improve healthcare quality, equity and cost-

effectiveness, which leads to higher client satisfaction and improved access for services. Social franchising enables the accessibility of FP/RH provision to low-income and hard-to-reach clients in rural and peri-urban areas through the network of providers. Incorporating a social franchising model with complementary social marketing strategies allows for sustained demand generation and supply of services to the target population. Additionally, the social franchising strategy of adopting tasksharing and task-shifting methods helps expand the network of healthcare providers. The training provided to midlevel providers such as midwives, nurses, and community outreach workers helps to deliver FP services across rural and peri-urban areas (USAID, 2011; Beyeler, 2013; Stephenson et al, 2004).

\section{GOAL OF THE PCVR-SOCIAL MARKETING/SOCIAL FRANCHISING MODEL}

The goal of the PCVR-SM/SF model is to increase access to and information about PCVR for postpartum women and their families through established social marketing and social franchising networks. The purpose of the project is to introduce PCVR across the total market (i.e. public, nonprofit and commercial sectors) and at varying prices to cater to the different income segments of the target population. In this effort, the project will integrate PCVR (in the method mix of existing PPFP products and services) into established social marketing and social franchising networks providing $\mathrm{FP} / \mathrm{RH}$ and $\mathrm{MCH}$ services.

\section{Key Objectives}

- To increase access to information about PCVR through effective social marketing strategies

- To meet the demand for postpartum contraception among women in low and middle income communities

- To manage and increase the supply of PCVR to public and private providers serving low and middle income communities. 


\section{The PCVR- Social Marketing and Social Franchising Model (PCVR-SM/SF)}

The purpose of the PCVR-SM/SF model is to assess the feasibility of the introduction and scale-up of PCVR through established social franchising outlets (supply) and social marketing of products and services to maximize uptake (demand) of PCVR among target populations.

The PCVR-SM/SF model as represented in Figure 2 incorporates some of the key components of an effective social marketing and social franchising system that will be required to launch PCVR in the targeted countries.

FIGURE 2: KEY COMPONENTS OF THE PCVR-SOCIAL MARKETING AND SOCIAL FRANCHISING MODEL

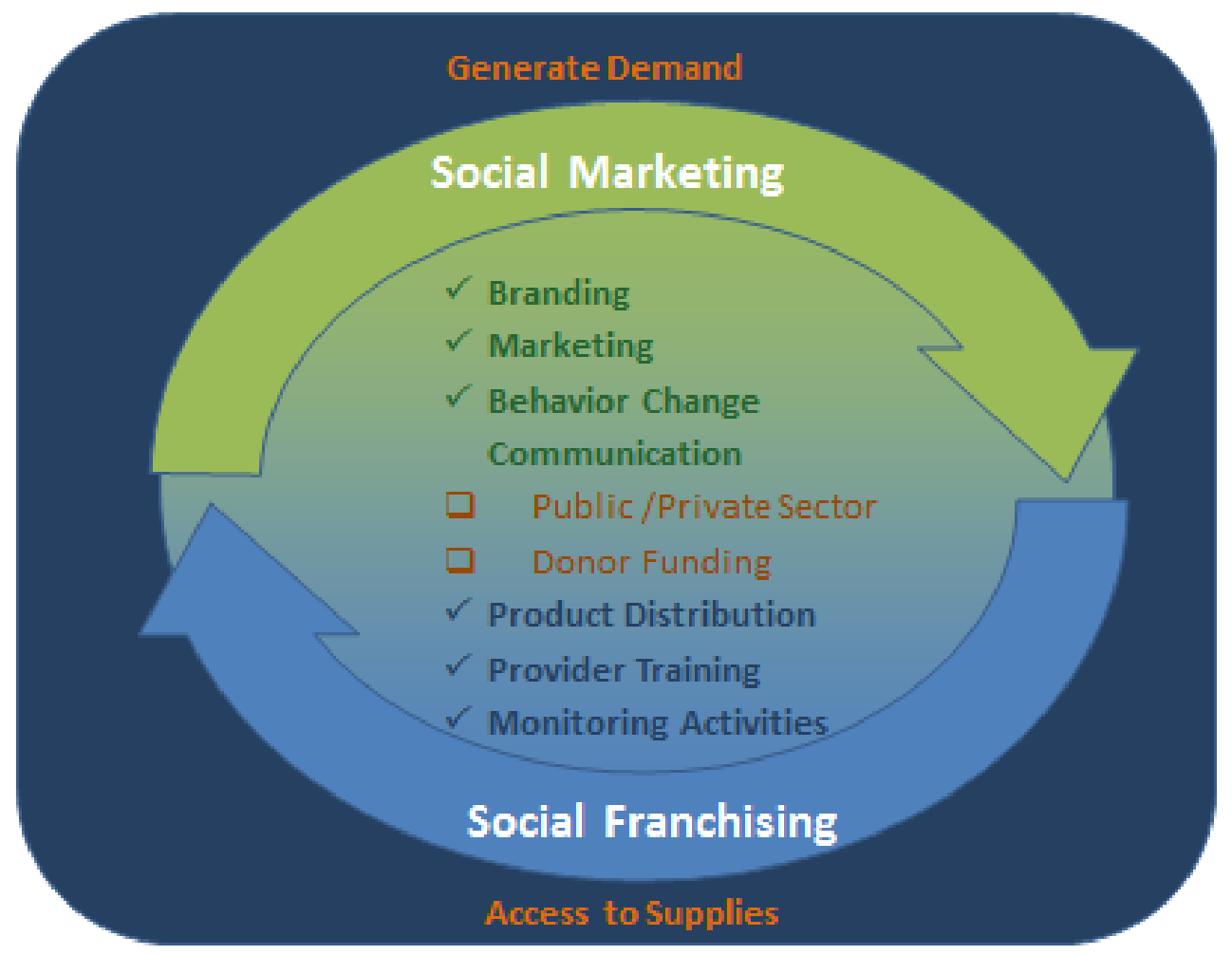

The outer ring of the wheel represents the on-going complementary demand and supply mechanisms for the PCVR-SM/SF model. On the social marketing side, effective demand generation strategies will include product branding; multi-media marketing and advertising as well as incorporating behavior change communication messages highlighting the benefits of postpartum family planning and use of PCVR as an effective contraceptive option. On the other hand, social franchising will address access to PCVR supplies through effective procurement and distribution channels. Established networks of healthcare providers and distributors including pharmacists and drug shop owners will need to be trained and regularly monitored to ensure adequate knowledge and skills for PCVR service delivery.The center of the wheel in Figure 2 represents the types of providers across the public and 
private healthcare facilities and the contingent "investor funds" that will be required to manage some of the demand and supply chain activities.

The PCVR-SM/SF model has been adapted from two leading social marketing and social franchising organizations that promote family planning products and services in developing countries. Both of these, Population Services International (PSI) and Marie Stopes International (MSI), have established networks of social franchisees in several priority countries in Africa, Asia and Latin America. Both of these organizations provide high-quality family planning services via clinics, mobile outreach units, and social franchising of private provider programs in over 53 countries. The model described here can be applied in leading SM/SF organizations currently operational in low-income countries such as PSI, MSI and DKT. (See Appendix 1 for details on the PSI and MSI models and how PCVR can be integrated).

\section{FIGURE 3: PCVR- SOCIAL MARKETING AND SOCIAL FRANCHISING PROCESS}

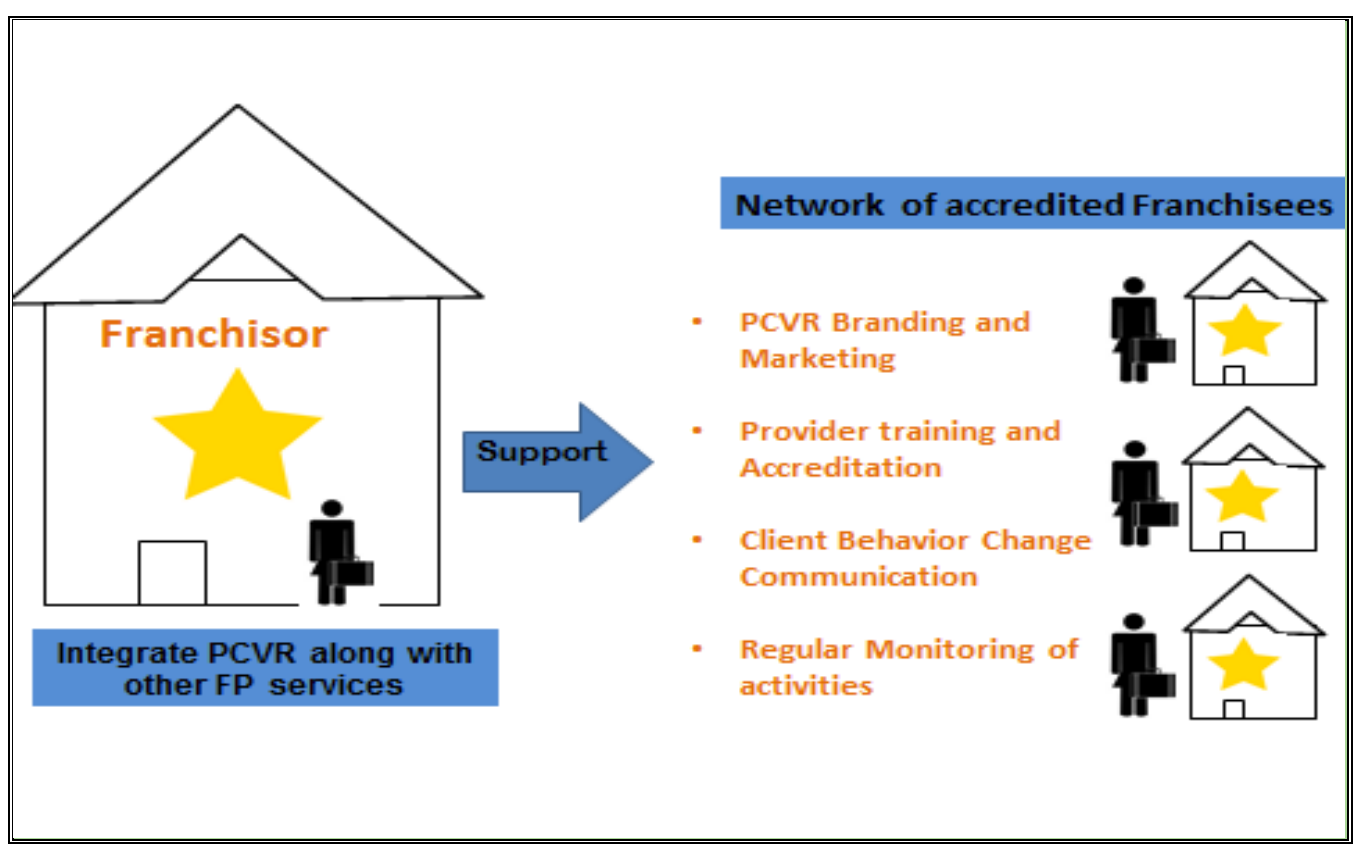

Figure 3 is adapted from prevalent business models such as those from PSI and MSI and represents some of the key processes for the successful functioning of the PCVR-SM/SF program and the integration of PCVR with established franchising systems. The Social Franchising Organization (SFO) or "Franchisor" will promote PCVR through its branded and accredited network of providers. The ongoing support for PCVR activities and packaged services will include: marketing and promotion of PCVR, provider training on how to counsel clients on the use of PCVR; client behavior change communication on postpartum family planning and the benefits of PCVR; and regular monitoring of PCVR activities undertaken by providers.

The implementation activities of the key components of the PCVR-SM/SF model are described in the following section. 


\section{Intervention Strategy: The 4 P's of Marketing}

The following section discusses the "marketing mix" for integrating PCVR into established social marketing and social franchising programs. These include: Providers, Promotion, Place and Price. These factors have been described in detail in the PCVR Market Development Plan (Chattopadhyay et al, unpublished).

\section{(1) PROVIDERS}

Providers of the PCVR-SM/SF model refer to the network of healthcare providers who are franchised by a SM/SF organization providing FP/RH services. As discussed in the sections above, these franchisees comprise a network of accredited public and private healthcare professionals providing postpartum family planning or child health services. This network includes: clinic-based physicians, mid-level health workers such as nurses, midwives and community health workers as well as pharmacists and drug shop owners.

There are several steps and considerations involved in integrating PCVR into an established SM/SF program. Upon identifying a targeted SM/SF organization, it will be necessary to conduct an in-depth review and analysis of the SM and SF systems as well as the FP/RH provider networks that may be interested in the product. This initial assessment may be carried out through stakeholder meetings and a brief survey to map interested provider networks in the targeted region.

A range of variables will need to be accounted for in the detailed design of the social franchising and marketing mechanisms. These include an assessment of the market types; varying levels of supply and demand; clients' knowledge of the range of family planning options and the clients' capacity and willingness to pay for services. It will also be necessary to review provider skills and experience of family planning; the array of franchising systems; financing strategies, and the review of various national and state government schemes and family planning programs (HIP, 2013).

The next step will require forming a technical advisory committee (TAC) comprising the key bodies Ministry of Health, drug regulatory authorities, $\mathrm{RH}$ advocates, healthcare providers, donors and the SM/SF organizations managing the provider network. The committee will aim to define the PCVR$\mathrm{SM}$ /SF intervention policies in the target country. These policies may include: the services covered, the cost of PCVR to providers and clients, training for providers and introductory costs for PCVR.

A stakeholder communication plan may be developed to address programmatic issues raised by the TAC. Key functions and activities of the stakeholder communication plan may include:

- Hosting periodic advisory group meetings to educate the stakeholders on the importance of introducing PCVR for PPFP and to address program issues, such as the design, cost, capacity development and management of quality control.

- Maintaining a stakeholder register to monitor on-going interactions, meetings, challenges, lessons learned and progress made on the program.

- Reviewing the potential for scale-up to increase access to PCVR in communities with a high unmet need for postpartum family planning. 
Finally, it will be important to ensure that all franchisees/providers undergo mandatory training on PCVR and follow compliance guidelines as per the franchising organization before being able to provide PCVR in the community (further details on training discussed in the latter section). The implementing partners may collaborate with the social franchising organization to organize initial training workshops for the franchisees. However, the franchising organization will also be responsible for managing support related to PCVR service delivery and for ensuring consistent quality of care.

\section{(2) PROMOTION}

Promotion is a salient feature of the PCVR-SM/SF model, and its main goal is to raise awareness and increase access to PCVR among the targeted providers, stakeholders and beneficiaries. The goal of promotion is to work with the local SM/SF organization to integrate PCVR into their ongoing social marketing strategy.

The 4 key suggested social marketing strategies for the promotion of PCVR include: 1) Behavior Change Communication, 2) Branding, 3) Marketing, and 4) Capacity Building of Providers

Behavior Change Communication (BCC) is a product-based social marketing strategy that incorporates a continuum of change in a client's knowledge, attitudes, beliefs and perceptions about a product. Along this continuum the client typically goes from being unaware of the product to being aware of it, then trying the product, then using it continuously, and eventually advocating its use to others (O'Sullivan, 2007). This product-based BCC method promotes general information about behavioral risks and is targeted toward hard-to-reach and at-risk clients.

A similar BCC strategy will need to be incorporated that is in line with the SM/SF organization in the target country. In the context of PCVR, a structured communication model may be designed based on the socio-demographic and socio-economic characteristics of the target population. Given that the majority of the targeted clients will be from low-income and middle-income communities, it will be necessary to ensure that messages are simple and brief; have a pictorial description of the product, a strong social message communicating the value proposition of the product to the consumer and the overall health benefits of PPFP. Furthermore, these messages may also debunk any myths and misconceptions about family planning and the use of PCVR. Lastly, it will be important to highlight any subsidies or discounts that will be provided on PCVR. This may be an attractive feature for socioeconomically disadvantaged clients who ould like to continue using the method (MSI, 2011).

Branding of RH products consists of a number of elements, such as specific names, logos, symbols, characters, packaging or slogans that identify and differentiate a product or service (Keller, 1998). Marketing, marketers may employ a set of brand elements to enhance awareness of a product with a strong social message that adds meaning to the consumer. Studies have shown that consumers tend to trust brands that they have used and they are more likely to purchase different services or products under the same brand name (Keller, 1998). To take advantage of this, the PCVR-SM/SF project will negotiate with established SM/SF organisations providing FP/RH products and services to integrate PCVR into their existing brand of products and services.

Marketing refers to the different channels of communications for promoting the product or service. The PCVR may be promoted through mass media (radio, television, billboards, print material, and the 
internet), interpersonal communication (client-provider interaction, group presentations) and community mobilization activities (mass campaigns and street plays). For example, education and promotion of PCVR may also be targeted through specific networks of women, for example through women's self-help groups or breastfeeding groups.

To facilitate this process, a marketing manual may be developed in collaboration with the local SM/SF organization to describe the various tools and channels for the promotion of PCVR. PCVR marketing materials may include posters, banners, leaflets, palm cards and brochures and will need to be designed based on the local context and language utilized by the SF/SM organization.

Capacity Building of Providers is a key component of the SM/SF program. All accredited franchisees will need to be trained on the PCVR method of contraception. A PCVR provider training package for the PCVR-SM/SF project may be developed and integrated into the provider programs that have been developed by the local SM/SF organization. The training modules may include topics on:

- Counseling and role-play modules to educate postpartum women on the benefits of family planning and provision of PCVR as a PPFP contraceptive option

- Importance of breastfeeding, the LAM method and the benefits of using PCVR following the continuum of care for PPFP

- Dissemination of Information, Education, and Communication (IEC) materials for promotion of PCVR

- $\quad$ Frequently asked questions on PCVR

- Quality assurance benchmarks for PCVR delivery

\section{(3) PLACE}

Place represents all the locations at which PCVR will be accessible to clients. The goal of the PCVR$\mathrm{SM} / \mathrm{SF}$ model is to make the vaginal ring available through public and private franchised networks across urban and rural areas.

The implementing partners may work with the SM/SF organization to map high-potential locations, such as clinics, pharmacies and community-based outlets providing maternal health and family planning products and services. A survey may be carried out to map the providers who might be interested in providing the ring at their clinics or outlets. This mechanism may be helpful in evaluating the potential demand and supply-chain mechanism in the community. Furthermore, based on the information collected during the pilot phase, the project may modify its marketing strategy in order to reach additional accredited providers and contracted distributors to provide PCVR.

Another key aspect of place is the need to map the procurement and distribution systems for PCVR. While most SM/SF organizations may have their own infrastructure to manage distribution, some countries may rely on outsourcing procurement and distribution, based on donor funding and the scale of the program. It is suggested that the SM/SF programs assess cost-effective distribution channels for promoting their products (O'Sullivan et al, 2007). The project implementers will need to work with the SM/SF organization to develop a local logistic-management system to ensure consistent supply of PCVR across the various service delivery points. For example, the PCVR manufacturer may collaborate with the local SM/SF organization to provide regular stocks for PCVR to the franchised network. 
Furthermore, given the ease of use of the vaginal ring and the non-clinical nature of its insertion and removal (eliminating the need for a skilled health provider's involvement), alternate arrangements may be made to provide PCVR directly through home-visits made by franchised CHWs. This strategy will reduce the need for the client to travel to healthcare facilities and will avoid further transportation and service cost. For example, it is expected that postpartum women who choose the PCVR would use between 2-4 rings in the first year following childbirth. With proper counseling, women may obtain up to 2 rings at a time to reduce the burden of follow-up. Additionally, ensuring that the PCVR is made available through the CHWs and other contracted social franchising outlets is an alternative strategy to reach women using the vaginal ring who may be lost to follow-up.

\section{PRICE}

The pricing strategy of PCVR will play an important role in the successful implementation of this intervention and will need to be addressed. Determining the right pricing strategy for the PCVR when integrated with other PPFP products and services will be central to the integration of the PCVR-SM/SF service delivery model.

According to USAID/HIP (2013), planning for sustainable funding is crucial from the start of a project. Country-specific pricing laws regulated by the Ministry of Health as well as funding from the government and other financial institutions will need to be assessed by the project prior to implementation. In the case of PCVR, a sustainable multi-year financial investment may be required to build a sustainable market.

Pricing of the PCVR following the SM/SF model will essentially be designed to fill the "gap in the middle," reaching those not served with free programs from the public sector or with high-priced commercial products targeted to the wealthiest segments. In reality, social marketing programs can be designed to also reach the poor, if product prices are subsidized sufficiently (USAID/HIP, 2013).

While all social marketing programs begin with some level of subsidy, there is discussion about how to ensure that subsidies are targeted to populations that are unable to pay full commercial prices. Some social marketing programs have introduced innovative financing mechanisms such as voucher programs to ensure that their products and services are accessible to special population segments. Donors have been attracted to this method because it appears to mobilize the private sector by recovering costs through the users and franchisees (Smith, 2002). According to PSI, the total market is about achieving a health marketplace where all segments of the society are reached according to their ability to pay: the poorest through free delivery; those somewhat better off through subsidized products and services; and those with greater ability to pay through commercially delivered products and services.

Three primary cost components need to be factored into the PCVR-SM/SF model. These include:

- Consumer Cost: the subsidized price of PCVR to the target population

- Program Management Cost: the administrative costs of setting up and running the PCVR-SM/SF Program

- Procurement Cost : the cost incurred by healthcare providers to purchase PCVR 
Initial pricing of the product may be estimated based on the price at which providers and procurers are willing to sell the vaginal ring and the pricet at which the users are willing to purchase the ring. The program implementers may opt to conduct a willingness-to-pay (WTP) study for PCVR among the users, providers and procurers. In general, pricing for the ring may be dependent on the user willingness to pay or the perceived market "value", the income level of the target segment and the convenience of the health sector providing the service.

A competitive and sustainable pricing strategy for PCVR will then need to be negotiated in collaboration with the franchisor, donor(s), governing bodies and supply-chain managers to review the WTP profile of the target population, the potential volume of procurement of the product as well as the estimated size of the targeted market and anticipated demand. Secondly, efforts will need to be made to identify financing strategies to subsidize the cost of the ring, including funding support from the government and other financial institutions.

Lastly, a budget plan may need to be created for the initial administrative costs during the early stages of the implementation process. Table 2 outlines the administrative and program management cost for PCVR-SM/SF model. These include some of the initial set-up costs as well as on-going cost to integrate and scale-up PCVR.

TABLE 2: ADMINISTRATIVE AND PROGRAM MANAGEMENT COST FOR THE PCVR-SM/SF MODEL

\begin{tabular}{|c|c|}
\hline Set up costs to introduce PCVR-SM/SF & Ongoing Costs for PCVR-SM/SF \\
\hline $\begin{array}{l}\text { - } \text { Pre-launch planning with franchisor, donors and MoH } \\
\text { - } \text { Review and adapt to on-going SM/SF system } \\
\text { - } \text { High-level advisory group meetings to launch PCVR } \\
\text { - } \quad \text { Development of IEC and Capacity Building materials for } \\
\text { PCVR } \\
\text { - } \quad \text { Kick-off marketing/advertising campaign for PCVR } \\
\text { - } \quad \text { Identify donors and procurers for PCVR-SM/SF } \\
\text { - } \quad \text { Establish monitoring and evaluation plan }\end{array}$ & $\begin{array}{l}\text { - } \quad \text { Program Management } \\
\text { - } \quad \text { Continued training of providers } \\
\text { - } \text { Monitoring and evaluation } \\
\text { - } \quad \text { Continued Marketing } \\
\text { - } \quad \text { Integration into logistic and supply } \\
\text { - } \quad \text { chains } \\
\text { Service provision }\end{array}$ \\
\hline
\end{tabular}

As listed in the table the administrative costs at the introductory stage of the PCVR project will have various costs associated with strategically identifying and introducing the ring to the key stakeholders. The cost of training and advocacy materials that will be designed relevant to the local context is another significant cost to set up the project. While some of these costs may be borne by the participating franchisor and/or franchisee, additional funding may need to be secured for the initial set up of the project. It is expected that with an increase in demand for PCVR and the reduction in the gradual administrative costs, the price of the product may be further reduced.

To demonstrate and evaluate the effectiveness of the PCVR-SM/SF intervention, the model may be introduced through franchised networks established by PSI, MSI and or DKT. As an example, a table has been created (see Appendix 2) to discuss the types of providers, promotional strategies, place of introduction and cost for undertaking the program through the MSI and PSI networks. 


\title{
Implementation of the Model in Three Phases
}

The following section lays out a timeline for the implementation plan. It is proposed that the implementation of the PCVR-SM/SF model be carried out in 3 phases:

- $\quad$ Phase 1: Design phase

- $\quad$ Phase 2: Start-up phase

- $\quad$ Phase 3: Scale-up Phase

Each phase will review the three key components: duration of the project, quantity of rings required, and the sites. Also each phase will be described in detail providing key recommendations for transitioning to the next phase and cohesively implementing the program.

\section{Phase 1: Design Phase}

The key goal of the design phase is to pilot test the PCVR-SM/SF model to evaluate the process and program functions. Based on the findings of the pilot test, modifications may be made to improve the program.

\author{
Duration: 2 years \\ - 6 months - pre-implementation planning \\ - 1 year - program implementation (pilot test in select sites) \\ - 6 months - program evaluation and modification
}

Quantity of rings: 400

Study sites: 4-8 private healthcare facilities

As part of the initial design testing phase, the PCVR-SM/SF intervention will be pilot-tested in 1 county or a particular district. From 4 to 8 study sites or private healthcare facilities will be selected to implement the model.Given that every interested postpartum women uses at least 2-4 rings in the first year following childbirth, the goal during this phase will be to reach between 100-200 women.

Initial cost for planning and administrative/programmatic costs will vary by country. The minimal personnel requirement for this program includes: 1 full-time program manager, 1 part-time finance manager to handle the management of funds and FAQs related to the program and on-going programmatic budgetary issues. A part-time administrative associate will be required to help with daily program logistics and operations. In addition, local program and outreach staff may need to be hired on a part-time basis to conduct additional research in target locations.

The evaluation will focus on making program modifications, based on provider interviews and minisurveys of participants who obtain products through the social franchisees. 


\section{Phase 2: Start-up phase}

During the second phase, the key goals of the PCVR-SM/SF model will be to integrate PCVR as a contraceptive option into the existing network of providers. Given that PCVR has been successfully registered in the country, and adequate procurement channels and supply chain agreements are in place, the development phase will involve implementing the PCVR-SM/SF model across all districts where the project is currently operational.

Duration: 2.5years

- 6 months - pre-implementation planning

- 1.5 years - program implementation across districts

- 6 months - evaluation and reporting

Quantity of rings: add forecasted number based on the geography and size of the target population) and the availability of the product from the manufacturer and procurers.

Study site: introduce at private healthcare facilities part of the franchised network providing $\mathrm{FP} / \mathrm{RH}$ services

\section{Phase 3: Scale-up Phase}

The goal of the scale-up phase is to expand the SM/SF model to new locations where there is a high unmet need for postpartum family planning. Secondly, depending on the success of the PCVR-SM/SF program, strategic communication and negotiations will be conducted with the social marketing and/or social franchising organization to expand services to other districts in the country.

Duration: 2 years

- 3 months - pre-implementation planning

- 1.5 years - program implementation across existing and new districts

- 3 months - evaluation and development of a policy guideline to integrate PCVR-SM/SF into the national action plan

Quantity of rings: add forecasted number based on the geography and size of the target population.

Study sites: introduce at diverse levels of healthcare facilities in new districts 


\section{Conclusion}

The Social Marketing and Social Franchising (SM/SF) mechanism may be an effective strategy to promote and deliver the PCVR through a larger network of private providers. This strategy has proved to be an effective mechanism of promoting access by complementing the public-sector family planning distribution system by utilizing the extensive network of commercial and nongovernmental sector outlets, such as pharmacies, shops, community-based distributors, private health providers/outlets, kiosks and community health workers (USAID, 2013).

Furthermore, the competitive pricing range of products allows the SM/SF model to reduce the gaps in equity, such as the geographic and socio-economic disparities in family planning use. The wider network of outlets and subsidized prices also allows the PCVR to be available to more underserved people, such as rural first-time users or younger people. For example, younger unmarried women may prefer to obtain contraceptive methods from private-sector sources, which tend to provide more anonymity than the public-sector sources (Meekers et al, 2001).

Another key benefit of this strategy is the sustainability of the FP/RH products in the market not only through strategic branding, marketing and behavior change communication messages but also through innovative funding mechanisms and a minimum fee that is attached to train providers and to cover the service rendered. Providers are incentivized to join and remain in the network by gaining access to training opportunities, supply of high-quality commodities, and promotional support. These incentives can improve the quality of care and encourage "self-regulation" for complying with quality and affordability standards (Beyeler et al, 2013).

In summary, the PCVR-SM/SF model is expected to work in situations where there is a high unmet need for family planning; sustained branding and behavior change communication is needed to educate the clients of PPFP and the benefits of PCVR; there is interest in promoting FP products and services among the private sector-outlets; and when clients have a modest ability to pay for family planning products and services (USAID/HIP, 2013). 


\section{References}

Armand, F. (2003). Social Marketing Models for Product-Based Reproductive Health Programs: A Comparative Analysis. Washington DC: USAID/Commercial Market Strategies Project

Barnes, J., Janet V., Dawn C. (2012). Total Market Initiatives to Reproductive Health. Bethesda, MD: Strengthening Health Outcomes through the Private Sector Project, Abt Associates.

Beyeler N., A.York De La Cruz, D.Montagu. (2013).The Impact of Clinical Social Franchising on Health Services in Low- and Middle-Income Countries: A Systematic Review. PLoS ONE 8(4): e60669. doi:10.1371/journal.pone.0060669

IFPS Technical Assistance Project (ITAP). (2012). Social Franchising as a Public-Private Partnership Model - Lessons Learned from the Merrygold Health Network of Uttar Pradesh, India. Gurgaon, Haryana: Futures Group, ITAP

Lane K. (1998). Branding Perspectives on Social Marketing, Advances in Consumer Research Volume 25, eds. Joseph W. Alba \& J. Wesley Hutchinson, Provo, UT: Association for Consumer Research, Pages: 299-302.

Marice Stopes International (MSI). (2011) Social Franchising: Reaching the underserved. Retrieved from http://mariestopes.org/sites/default/files/Social-franchising-Innovations-FINAL.pdf

O'Sullivan, G., Cisek C., J. Barnes, and S. Netzer. (2007). Moving Toward Sustainability:Transition Strategies for Social Marketing Programs. Bethesda, MD: Private Sector Partnerships-One project, AbtAssociates Inc.

Population Services International. (2014). Social Marketing Evidence Base. Retrieved from http://www.psi.org/research/evidence/social-marketing-evidence-base/

Ross J. and Winfrey W. (2001) Contraceptive Use, Intention to Use and Unmet Need during the Extended Postpartum Period. International Family Planning Perspectives, Vol. 27, Number 1, New York: Guttmacher Institute.

Smith E. (2002). Social Franchising Reproductive Health Services: Can It Work? A Review of the Evidence. Marie Stopes International.

Schlein K. and D.Montagu. (2012). Clinical Social Franchising Compendium: An Annual Survey of Programs. San Francisco, CA: Global Health Group, Global Health Sciences, University of California San Francisco

USAID/High-Impact Practices in Family Planning (HIP). (2013). Social marketing: leveraging the private sector to improve contraceptive access, choice, and use. Washington, DC: USAID.

Viswanathan, R., Schatzkin, E., and Sprockett, A. (2014). Clinical Social Franchising Compendium: An annual survey of programs: findings from 2013.San Francisco: The Global Health Group, Global Health Sciences, Universityof California, San Francisco.

USAID/SHOPS. (2013). Assessments: The First Step in Engaging the Private Health Sector. Washinton D.C.: Abt Assocaites 


\section{Appendices}

\section{APPENDIX 1}

\section{ILLUSTRATIVE EXAMPLES OF ONGOING SM/SF PROGRAMS IN SUB-SAHARAN AFRICA}

\section{Described below are examples of current PSI, MSI and DKT SM/SF programs and networks in 3 countries: Kenya, Nigeria and Senegal}

- In Kenya, both MSI and PSI have a strong presence of social marketing networks. MSI/Kenya's Flagship program, i.e. BlueStar network, provides FP/RH services through over 600 private and public operational sites across Kenya. Additionally MSI also manages a fractional social franchise called AMUA for the Government of Kenya (Social Franchising Compendium, 2013). The AMUA network currently consists of over 280 centers (58 hospitals and 222 clinics). PSI/Kenya has 3 flagship programs in Kenya, including FEMIPLAN, TUNZA Family Health Network (15hospitals, 280 clinics; 46\% rural, 54\% urban) and The C-word, which provide FP/RH services. The Tunza clinics provide family planning services with an emphasis on long term reversible methods (PSI, 2010).

The goal of the TUNZA project was to engage with a network of private health providers and empower low-income Kenyan women to avoid unplanned pregnancies. The Tunza model follows a 2-pronged approach which includes quality and standardization of a network of health care providers (supply side) and the demand creation by a dedicated marketing team. The Tunza franchise recruits and trains private practitioners in the provision of LARC servcies. It also promotes the acceptability of LARCs in the community. In general clients prefer going to private healthcare facilities over the public sector as they have superior facilities and infrastructure. Kenya public health system - community, dispensaries, health centers, sub-district and district level hospitals, provincial hospitals, national teaching and referral hospitals

- In Nigeria, PSI has fairly established fractional franchise networks and collaborates with its implementing partner Society for Family Health (SFH), which is a government led organization. SFH markets various FP/RH products through 150 outlets across Nigeria. About $60 \%$ of the SFH networks are in rural areas and $40 \%$ in urban areas (Schlein and Montagu, 2013). Given SFHs strong presence in the country, it will be beneficial to assign PSI/Nigeria as one of the market authorization holders. DKT is in its early stages of establishment in Nigeria and aims to promote and provide a variety of contraceptive options in the country. DKT/Nigeria has directly expressed interest in purchasing and promoting PCVR in Nigeria. Unlike PSI or MSI, DKT is quasi-commercial organization and is not donor dependent.

- In Senegal, ADEMAS (Agence de Développement du Marketing Social) was established in 1998 by the USAID funded Social Marketing for Change (SOMARC) project to provide FP/RH services in the country. PSI currently partners with the ADEMAS network to promote these services. The ADEMAS network comprises of 767 active pharmacies and 133 depots.In addition, Senegal also has MSl's Blue Star Network, which was launched in 2012 and currently operates through 34 clinics in the country. 


\section{APPENDIX 2}

\section{A DEMONSTRATIVE EXAMPLE: INTEGRATION OF PCVR WITH THE MSI AND PSI SOCIAL MARKETING AND SOCIAL FRANCHISING PROGRAM}

The table below describes the MSI and PSI service delivery models and highlights the adoption of the marketing mix to introduce the PCVR through social franchising and social marketing.

\begin{tabular}{|c|c|c|c|c|}
\hline Model & Place & Provider & Promotion & Price \\
\hline $\begin{array}{l}\text { MSI \& } \\
\text { PSI } \\
\text { Model }\end{array}$ & $\begin{array}{l}\text {-Site selection, } \\
\text { development and } \\
\text { management. } \\
\text {-Static clinic } \\
\text { located in urban } \\
\text { areas/slums. } \\
\text { Serves as a base } \\
\text { for training } \\
\text { providers. } \\
\text {-Mobile outreach } \\
\text { - visit } \\
\text { communities with } \\
\text { limited access to } \\
\text { modern fp } \\
\text { methods - rural } \\
\text { villages, urban } \\
\text { slums. }\end{array}$ & $\begin{array}{l}\text {-Partner with existing } \\
\text { private healthcare } \\
\text { providers in small towns } \\
\text { and urban areas. } \\
\text {-Doctors, midwives, } \\
\text { nurses, community health } \\
\text { workers. } \\
\text {-Provider training and } \\
\text { performance } \\
\text { management. } \\
\text {-Building public-private } \\
\text { partnerships. }\end{array}$ & $\begin{array}{l}\text {-Pre-visit demand } \\
\text { generation activities are } \\
\text { conducted with local } \\
\text { healthcare workers, } \\
\text { midlevel HCPs. } \\
\text {-Social Marketing } \\
\text { through provider } \\
\text { networks. Create a } \\
\text { branded network of } \\
\text { providers. } \\
\text {-Define guidelines on } \\
\text { what franchisees are } \\
\text { expected to do to } \\
\text { deliver on what the } \\
\text { brand promises. }\end{array}$ & $\begin{array}{l}\text {-Competitive pricing in } \\
\text { urban areas, income } \\
\text { generated from clinics } \\
\text { in wealthier area. } \\
\text {-Provides free, } \\
\text { subsidized FP } \\
\text { services. } \\
\text {-Health insurance, } \\
\text { vouchers. }\end{array}$ \\
\hline $\begin{array}{l}\text { PCVR } \\
\text { Service } \\
\text { Delivery }\end{array}$ & $\begin{array}{l}\text { Introduce PCVR } \\
\text { across } \\
\text { established MSI, } \\
\text { PSI network of } \\
\text { providers. }\end{array}$ & $\begin{array}{l}\text {-Establish goals with MSI } \\
\text { and PSI specific to each } \\
\text { country of operation. } \\
\text { - Assess the size of the } \\
\text { network, community } \\
\text { reach - urban / rural } \\
\text { distribution, develop } \\
\text { demand generation } \\
\text { activities for PCVR. } \\
\text { - Assess level of } \\
\text { community mobilization } \\
\text { required based on socio- } \\
\text { cultural norms and } \\
\text { practices related to } \\
\text { contraceptives. } \\
\text {-Check if franchisees are } \\
\text { a recognized and trusted } \\
\text { brand, standardized } \\
\text { operating system }\end{array}$ & $\begin{array}{l}\text {-Create a brand name } \\
\text { for PCVR. } \\
\text {-Prepare a checklist for } \\
\text { launching a new service } \\
\text { in an existing franchise. } \\
\text {-Communication } \\
\text { material on PCVR - for } \\
\text { providers and } \\
\text { consumers. } \\
\text {-Develop provider } \\
\text { manuals and tools for } \\
\text { PCVR education and } \\
\text { service delivery. } \\
\text { Promotional materials - } \\
\text { brand poster, clinic } \\
\text { boards, booklets, } \\
\text { leaflets, bill boards, } \\
\text { YouTube video, radio, } \\
\text { clinic merchandising }\end{array}$ & $\begin{array}{l}\text {-Work on voucher } \\
\text { schemes for low- } \\
\text { income clients. } \\
\text {-Vouchers can be } \\
\text { made available to } \\
\text { qualifying clients } \\
\text { either through CHWs } \\
\text { or healthcare } \\
\text { providers. } \\
\text {-The project may } \\
\text { partner with the public } \\
\text { and private sector } \\
\text { donor agencies to } \\
\text { determine pricing and } \\
\text { provision of } \\
\text { subsidized funding } \\
\text { schemes for the low- } \\
\text { income groups for } \\
\text { PCVR. }\end{array}$ \\
\hline
\end{tabular}




\section{APPENDIX 3}

\section{SYNOPSIS OF THE PCVR-SOCIAL MARKETING AND SOCIAL FRANCHISING MODEL}

The PCVR-SM/SF Model represents a strategy to integrate PCVR into the existing social marketing and social franchising programs that promote and provide FP/RH products and services.

The PCVR-SM/SF model will incorporate effective demand generation and supplychain mechanisms to increase awareness and expand access to quality service delivery of PCVR among postpartum women.

The key strategies for implementation of the PCVR-SM/SF model have been described utilizing the 4 P's of Marketing:

\section{Providers}
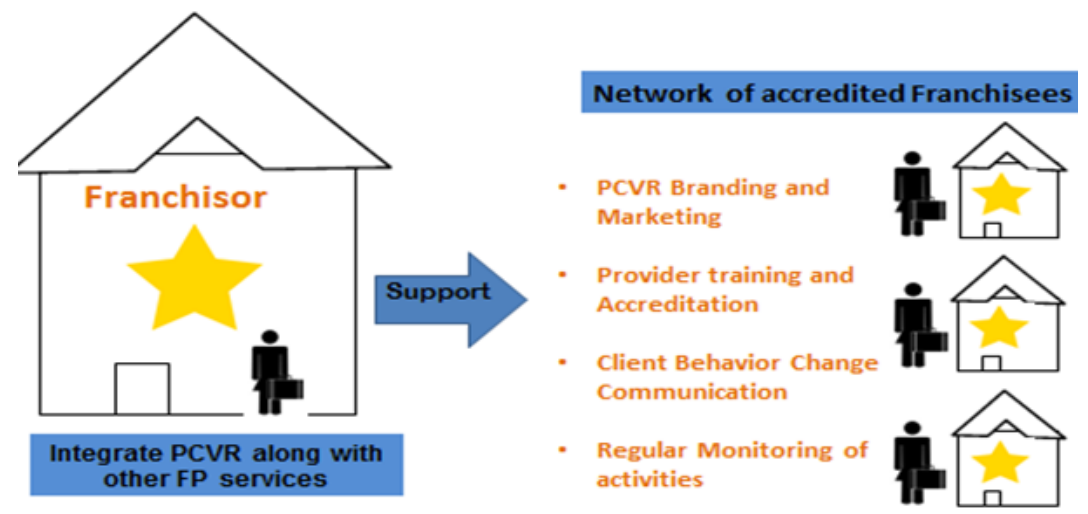

$\checkmark$ Identify and review the functions of the targeted social marketing /social franchising (SM/SF) organization

$\checkmark$ Conduct a brief survey to map interested providers in the targeted region

$\checkmark$ Convene an introductory meeting with the SM/SF organization and providers interested in the product

$\checkmark$ Form a technical advisory committee (TAC) to define the PCVR-SM/SF intervention policies in the targeted area

$\checkmark$ Organize training workshop with the franchisees along with the social franchising organization

\section{Place}

$\checkmark$ Map out the accredited network of providers interested in PCVR

$\checkmark$ Collaborate with the SM/SF organization to develop an efficient logistic-management system to ensure consistent supplies of PCVR across the network or interested franchisees

$\checkmark$ Make alternate arrangements for availability of PCVR through home-visits made by franchised CHWs

\section{Promotion}

$\checkmark$ Collaborate with the SM/SM organization to integrate PCVR information into social marketing strategies of behavior change communication, branding, marketing and capacity building of the accredited providers

$\checkmark$ Plan a strategy of dissemination through the different channels of communication

\section{Price}

$\checkmark$ Determine the manufacturing cost and volume of procurement for PCVR in the targeted area

$\checkmark$ Determine client willingness to pay, regulatory pricing laws and available funding

$\checkmark$ Determine the subsidized price of PCVR to the target population

$\checkmark \quad$ Plan of sustainable multi-year funding to ensure the availability of PCVR at a subsidized price

$\checkmark$ Factor in initial set up cost and on-going cost to integrate PCVR into the existing SM/SF programs

The key stages of implementation of the PCVR-SM/SF intervention (3 phases):

$\checkmark$ Design phase: Pilot test the model in one district or county

$\checkmark$ Start-up Phase: Integrate PCVR as a contraceptive option across all interested districts with accredited providers

$\checkmark$ Scale-up Phase: Introduce the PCVR-SM/SF model to new locations where there is an unmet need for PPFP 



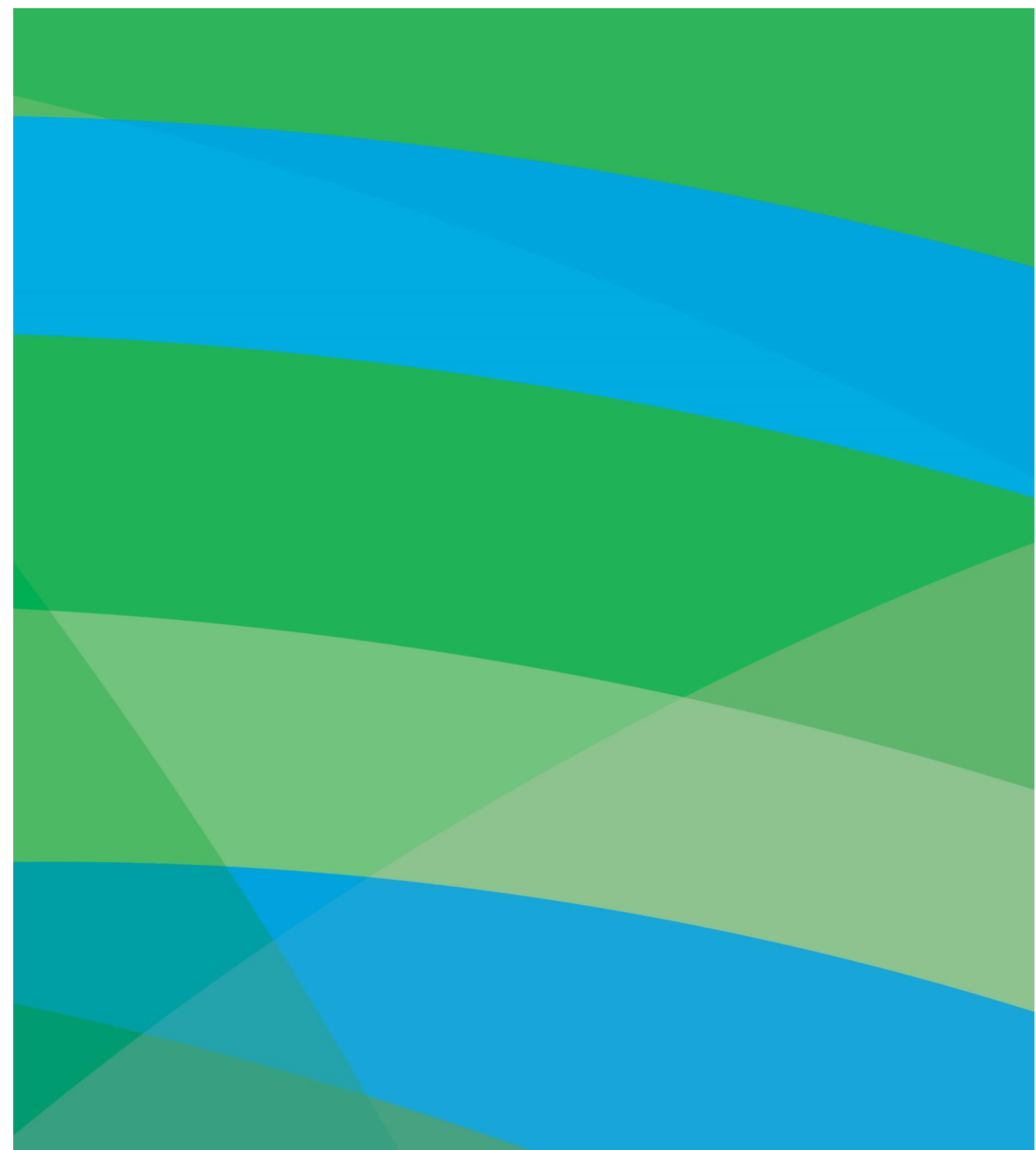

Population Counci

POPULATION COUNCIL

Ideas. Evidence. Impact.
4301 Connecticut Avenue NW

Washington DC 20008, USA

popcouncil.org 